\title{
Correction to: Regional Tsunami Forecasting: Uncertainties Due to Non-uniform Slip
}

\author{
C. Mueller, ${ }^{1}$ (D) D. Burbidge, ${ }^{1}$ and W. Power ${ }^{1}$
}

Correction to: Pure Appl. Geophys.

https://doi.org/10.1007/s00024-021-

02845-5

Figure 1 of the original version of this paper was inadvertently published with a wrong caption.

The correct caption is:

Example tsunami threat level map (detail) for a $M_{w} 8.7$ earthquake located $174^{\circ} \mathrm{W}, 14.9^{\circ} \mathrm{S}$ on the northern Tonga Subduction Zone. The arrival times at the coastal zones are also indicated.

The original article has been corrected. We apologise for any inconvenience caused to our readers.

The original article can be found online at https://doi.org/10.1007/ s00024-021-02845-5.

1 GNS Science, 1 Fairway Dr, Lower Hutt 5010, New Zealand. E-mail: c.mueller@gns.cri.nz 